\title{
Review Article \\ Highlight on the Mathematical Modeling of Controlled Free Radical Polymerization
}

\author{
Mamdouh A. Al-Harthi \\ Department of Chemical Engineering, King Fahd University of Petroleum \& Minerals, Dhahran 31261, Saudi Arabia \\ Correspondence should be addressed to Mamdouh A. Al-Harthi; mamdouh@kfupm.edu.sa
}

Received 15 October 2014; Accepted 8 March 2015

Academic Editor: Frederik Wurm

Copyright ( 2015 Mamdouh A. Al-Harthi. This is an open access article distributed under the Creative Commons Attribution License, which permits unrestricted use, distribution, and reproduction in any medium, provided the original work is properly cited.

Over the last quarter century, controlled free radical polymerization (CFRP) has received great attention by the researchers of polymer science and engineering. In addition to the experimental studies, many publications in the literature dealt with the modeling of CFRP processes. A review of acknowledged and well-received researches on mathematical modeling in the area of CFRP is presented in this work. Three main categories of CFRP (namely, ATRP, RAFT, and NMP) are taken into consideration in the review. The different techniques used in modeling CFRP processes are also enumerated with more emphasis on Monte Carlo simulation and the method of moments. The review provides a better understanding of the processes and the recent efforts to model CFRP.

\section{Introduction}

Well-defined macromolecular architectures can be produced easily using controlled free radical polymerizations [1-4]. Mainly three CFRP mechanisms are well known in the literature: (1) nitroxide mediated polymerization (NMP) $[5,6]$, (2) reversible addition fragmentation chain transfer (RAFT) $[7,8],(3)$ and atom transfer radical polymerization (ATRP) $[3,9]$.

Mathematical models were used primarily to understand the mechanism of the polymerization processes while offering the advantage of avoiding tedious and expensive experiments. Modeling offers further insight into the process which can be used for tailoring experiments. Figure 1 shows the importance of modeling and its association with other areas of research for commercialization of new products and processes. Several CFRP characteristics were explained with the support of mathematical models by using the technique of moments, the Monte Carlo simulation, and PREDICI software. Recently new methods such as the probability generating function (pgf) transformation have also been used to model CFRP. The method of moments is one of the oldest modeling techniques that explain monomer conversion, average molecular weights, and compositions of the copolymers, but it does not calculate the full distributions of molecular weights (MWD) and distribution of chemical composition (CCD). PREDICI is commercial software developed to model polymerization which explains the balances of polymer population statistically and can forecast both MWD and CCD. The Monte Carlo simulation is another important tool, which simulates any polymer microstructural distribution and it is comparatively easy to apply. A review of the work done on modeling CFRP techniques is of utmost importance and value to researchers working in this exciting field.

The review starts from the inception of controlled/living radical polymerization in 1969 to the recent efforts in the modeling of ATRP, NMP, and RAFT. The review involves both homopolymerization and copolymerization. The use of different modeling techniques pertaining to ATRP, NMP, and RAFT is the focus in this review.

\section{Controlled/Living Free Radical Polymerization}

In 1969, Borsig et al. first reported the concept of controlling radical polymerization. The group used bulky diaryl and triaryl ester groups on methacrylate monomers and observed 


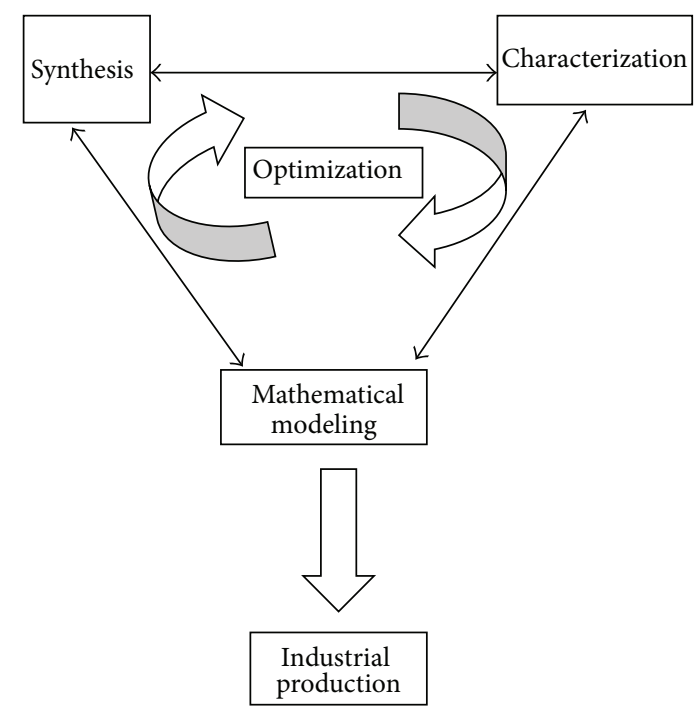

FIGURE 1: Various stages in the commercialization of new products and processes.

a rise in the molecular weight with conversion. Formation of the block copolymers was inferred [10]. The process still suffered from low initiation efficiencies and the polydispersity index (PDI) was relatively high (the ideal PDI should approach one). The relationship between molecular weight and conversion was also not linear.

It was only later in 1982 that the term CFRP was coined by Otsu and Yoshida during their work on the iniferter mechanism [11]. They used tetraethylthiuram disulfide in thermal/photo polymerization of styrene and MMA and got functionalized polymers having initiator fragments and chain terminators. Another work by Otsu and Kuriyama [12] utilized an S-alkyl dithiocarbamate group which undergoes reversible photodissociation to a reactive alkyl radical and an inert dithiocarbamate group. However, the use of dithiocarbamates hindered the living nature of the chain end due to decomposition of dithiocarbamates.

The concept of using transition metal compounds for the formation of persistent radicals to produce polymers in a controlled manner was also investigated. In 1978, Lee and Minoura polymerized methyl methacrylate (MMA) introduced by benzoyl peroxide (BPO) in the presence of chromium (III) acetate [13]. The group reported an increase in molecular weight with conversion and formation of the block copolymers. There are several reviews that covered the subject of CFRP using transition metals $[14,15]$.

In 1985, Solomon et al. [16] introduced the concept of stable free radical polymerization using persistent nitroxyl radicals. The authors reported that the rate-limiting step for the formation of well-defined polymers was affiliated with the degenerative transfer of alkoxyamine between polymer chains. However, it was Georges et al. [17] that gave a more precise understanding of the process in their first publication. They reported the polymerization of styrene with benzoyl peroxide as normal free radical initiator and TEMPO as stable free radical initiator. They produced polystyrene with a PDI of 1.26. They inferred that the PDI remains constant over the entire course of the reaction, proposing that the reaction proceeds via a type of living chain mechanism. The increase in molecular weights with time also suggested that the reaction proceeds thru a type of living polymerization. The control of the polymerization was attributed to the homolytic cleavage of the polymer chain and TEMPO adduct. This led to the concept of nitroxide mediated polymerization.

Another approach to produce controlled polymers is based on degenerative transfer reactions. In this process, control is achieved by a thermodynamically neutral exchange of a group between the growing radicals, present at very small concentration, and dormant chains, present at a higher concentration. If the exchange reactions are very fast relative to propagation reaction, the resulting polymers have low PDI. Various alkyl iodides were used as transfer agents. Chiefari et al. [18] used thiocarbonylthio compounds as transfer agents and became the pioneer in establishing the process called RAFT.

The challenge to create controlled polymers resulted in the process called ATRP in 1995. The review of these three prominent processes, namely, (1) NMP, (2) RAFT, and (3) ATRP, is dealt with in the following sections. This review is focusing on mathematical modeling that was used to study these three types of CFRP.

\section{Nitroxide Mediated Polymerization (NMP)}

Rizzardo et al. and George et al. were the pioneers in establishing the process of NMP as explained in the previous section. However, it was only in 1996 that the first work on modeling NMP was initiated by Veregin et al. [19]. George and coworkers modeled NMP using a kinetic approach formed to find the effect of rabid exchange between radicals and dormant species in the group transfer polymerization. A generalized solution was derived for the MWD as a function of conversion. They only considered the rate constants for propagation, trapping of the growing chains by the nitroxide radical, and the release of the growing chain. They obtained a very good fit between their modeling and the experimental results. The group made their conclusion that polydispersity index in the bulk CFRP mediated by nitroxide was controlled by the exchange rate between the living and dormant species.

In 1997, Fukuda et al. [20] investigated the mechanism and kinetics of nitroxide mediated polymerization for the polymerization of styrene at high temperature. They included thermal initiation, dialkyl termination, the decomposition of the active chain end, and the stationary state with respect to radical concentration. The model was developed using the method of moments to quantify polydispersity index, average molecular weight, and conversion. A better fit was obtained against the investigational data for polymerization of styrene. Similarly Monte Carlo method was applied to model NMP by He et al. [21] in 1997. They predicted the chain length distribution obtained in CFRP using a hybrid Monte Carlo simulation. They modeled two classes of living radical polymerizations, one which was introduced by alkoxyamines and the other by nitroxide 


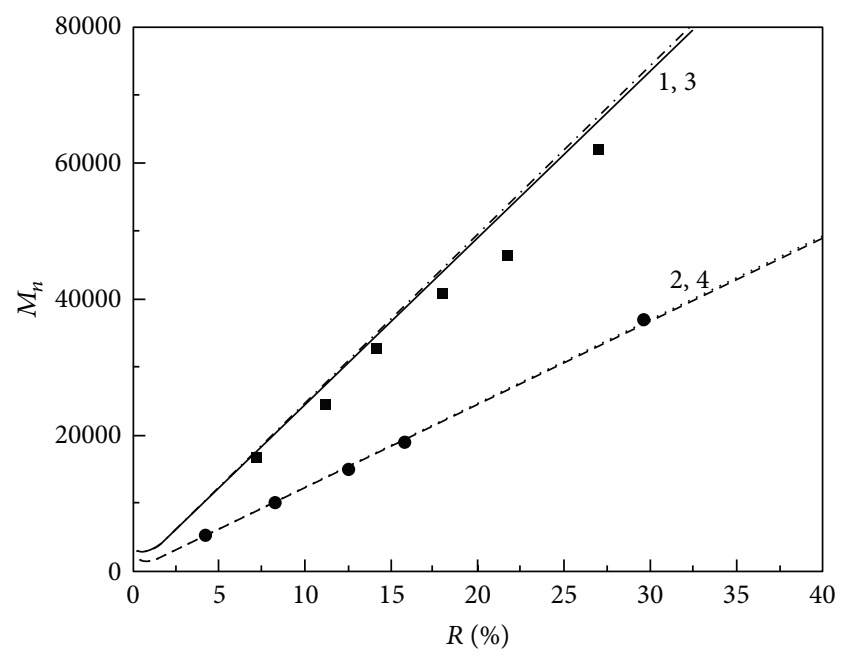

- Experimental data for $[\mathrm{SR}]_{0}=3.7 \times 10^{-3} \mathrm{~mol} / \mathrm{L}$

- Experimental data for $[\mathrm{SR}]_{0}=7.4 \times 10^{-3} \mathrm{~mol} / \mathrm{L}$

FIgURE 2: Dependence of $M_{n}$ on conversion for styrene bulk polymerization at $90^{\circ} \mathrm{C}$. The lines represent the simulated data and the dots present the experimental results. The full parameters and experimental conditions are available in [21].

radical, 2,2,6,6-tetramethyl-1-piperidinyloxy, mediated radical polymerization. They studied the effect of different experimental parameters, such as reactant concentrations and rate constants on the kinetics and MWD. They made a contrast assessment between the experimental and simulated results. It was concluded that, taking thermal initiation into consideration, the model fits the experimental data very well as in Figure 2.

Later in 1999, Shipp and Matyjaszewski [22] made a comprehensive model for ATRP, NMP, and RAFT. The work contrasted with their predecessors as they made a comparison between the three polymerization processes. They compared rates, molecular weight, and functionality between them. The factors leading to deviation from the living behavior were also clearly discussed. This was one of the papers which concentrated on the three methods in unison. He et al. continued their work on using Monte Carlo simulations for better understanding of the process of NMP. In the year 2000, He and coworkers [23] extended their previous work by studying four rate enhancing cases of NMP by the Monte Carlo method. They studied the kinetics and MWD of the polymers. They inferred that the equilibrium between living and dormant species shifted towards the growing ones in all four cases. They also studied the optimization of rate enhancement in living free radical polymerization.

Fischer et al. [24-29] developed kinetic models that showed the change of radicals (both nitroxide and propagating) with time. These kinetic models (known as Persistent Radical Effect) proved that the concentration of radicals is not constant with time. These basic models are very important to understand the equilibrium rate constants between the dormant and the radicals species.
In 2002, Bonilla and coworkers [30] formed a comprehensive kinetic model for NMP of styrene. They considered all the prominent reactions, many of which were neglected in previous modeling efforts. The reaction mechanism included the reactions such as chemical initiation, monomer dimerization, reversible nitroxyl ether decomposition, propagation, thermal initiation, reversible polymeric and monomeric alkoxyamine formation, rate enhancement, alkoxyamine decomposition, transfer to both dimer and monomer, and conventional termination. The detailed mechanistic discussions and qualitative simulations presented by the researchers provided a deeper insight into different aspects of the NMP process.

Schulte et al. [31] extended the work on nitroxide mediated polymerization of styrene by varying the concentration of alkoxyamine. The group examined the effect of the variation of the alkoxyamine concentration on conversion and polydispersity index. Four different alkoxyamines were studied and the modeling of nonlinear dynamics was discussed by this group. In 2006, Guillaneuf et al. [32] used the commercial software PREDICI to analyze the validity of kinetic rate constants used for the NMP of MMA using the new crowded SG1-based alkoxyamine. They concluded that kinetic rate constants being used were incorrect and the strong penultimate effect drastically increased the equilibrium constant preventing a well-controlled polymerization. Gigmes et al. [33] studied the living characteristics of NMP by using PREDICI software. The simulation was used to show the difference between living and controlled polymerizations. The value of the equilibrium rate constant can shift the polymerization from living process only to controlled process only or to neither one.

Batch reactors have been used primarily in all the modeling cases explained above. Modeling NMP of styrene in a CSTR was discussed by Lemoine-Nava et al. [34] in 2006. The group investigated the nonlinear behavior of NMP happening in a Continuous Stirred Tank Reactor (CSTR). The flow rate and temperature of cooling water, temperature of feed stream, residence times, and reactant concentrations were selected as the bifurcation variables. They provided a broad picture of using NMP for the large scale production of this class of polymers. Even though Lemoine-Nava and coworkers modeled NMP in a CSTR exclusively, Zhang and Ray [35] utilized a CSTR to model CFRP using the method of moments in 2001. They analyzed ATRP and NMP in various reactors such as batch, semibatch, and CSTR. He et al. validated their results against investigational figures for nitroxide mediated styrene homopolymerization and atom transfer radical copolymerization of n-butyl acrylate and styrene. The group gave theoretical differences obtained while using different reactors. They concluded that semibatch reactors were best suited for making polymers with controlled architecture.

The idea of utilizing semibatch reactors to produce polymers with controlled architecture has interested many researchers working in the field of living polymerization. Fu et al. [36] utilized a semibatch reactor to model NMP. The group developed a mechanistic model for relatively high temperature $\left(138^{\circ} \mathrm{C}\right)$ styrene polymerization in semibatch 


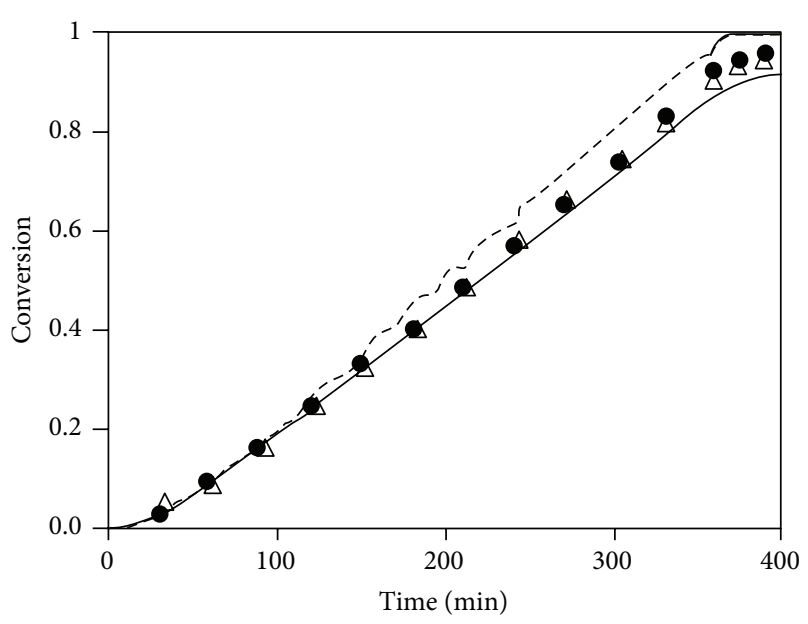

(a)

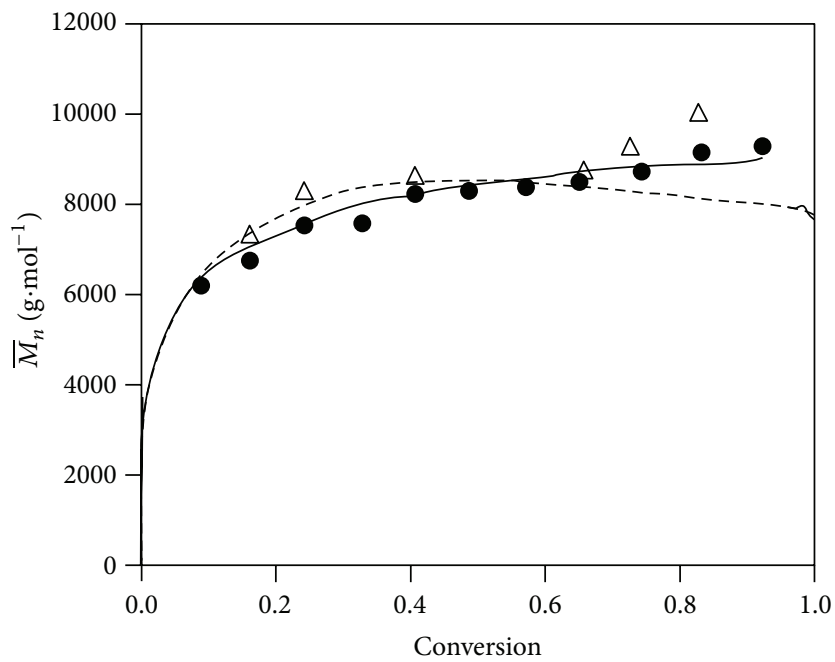

(c)

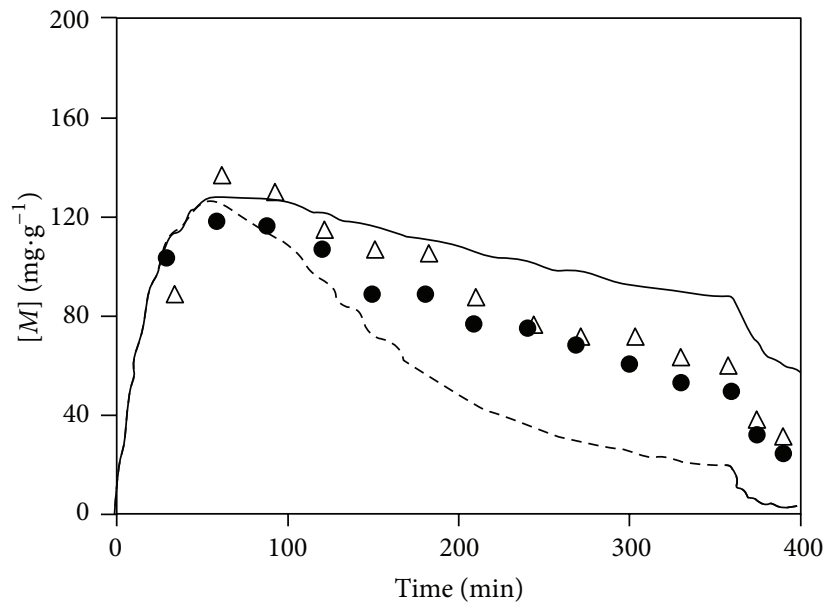

(b)

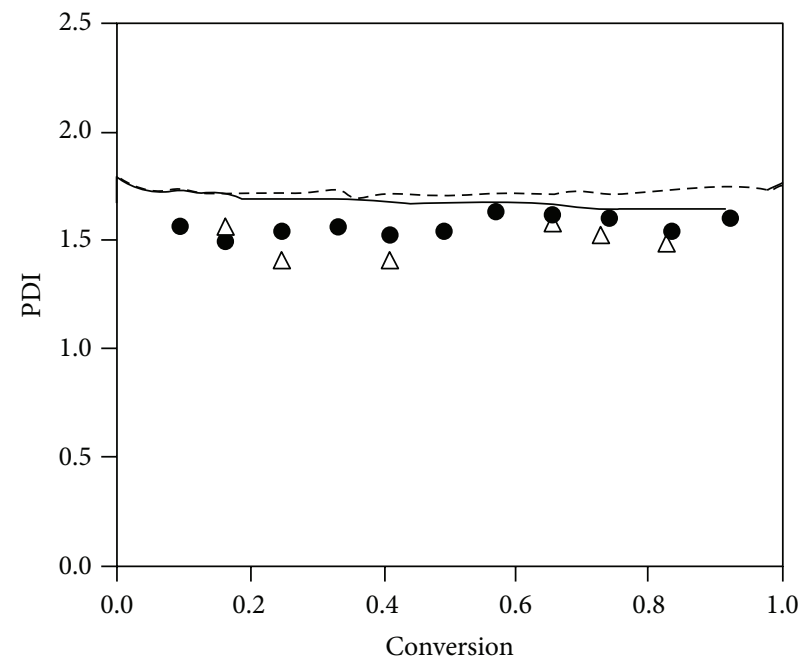

(d)

FIGURE 3: Free radical polymerization of styrene in semibatch reactor: (a) conversion versus time; (b) monomer concentration versus time; (c) $\bar{M}_{n}$ versus conversion; (d) PDI versus conversion. The solid lines are the simulation results without gel effect correlation and the dash lines are the simulation results with gel effect correlation. The dots are the experimental results. The full parameters and experimental conditions are available in [36].

reactor. The group incorporated the gel effect associated with the termination reaction to model NMP. They concluded that application of a gel effect correlation to characterize the variation in the diffusion controlled termination rate constant with monomer conversion leads to significant improvement in fitting the model to the experimental results. Figure 3 presents the comparison between the experimental data and the model with and without gel effect. However, it is not needed to represent the creation of low molecular weight material by usually initiated FRP or NMP.

The years of 2007 and 2008 saw the development of another technique called the probability generating function and the utilization of tubular reactors in living radical polymerization. Asteasuain and coworkers [37] developed an instrument for designing NMP process in tubular reactors to achieve ideal MWDs. Their objective of predicting the MWD was achieved exactly and efficiently by means of the probability generating function (pgf) transformation. They also obtained a good fit against the experimentally available data. They showed the potential of the resulting model for optimization activities involving the complete MWD. Later in 2008, the same group published another paper to model NMP while giving more emphasis on optimization of the process in a tubular reactor [38]. These were the modeling efforts done in the field of NMP.

Although most of the authors either have avoided the effect of diffusion or have only considered the bimolecular termination to model NMP, some researchers considered the diffusing effect in their models. Roa-Luna et al. [39] qualitatively modeled the effect of diffusion controlled reactions in NMP. The group developed a kinetic model for NMP of styrene by considering diffusion effects in the main polymerization steps (elementary reactions). They used free volume theory to study the importance of diffusion. They 
concluded that diffusion controlled termination improves the living behavior of the system, whereas diffusion controlled propagation, diffusion controlled activation, and deactivation worsen it. Belincanta-Ximenes et al. [40] also simulated the polymerization of styrene using monomolecular and bimolecular initiators. They studied the effect of using different reaction temperatures. They simulated the molecular weight, polymerization rate, development, and evolution of the concentration of all species taking part in the mechanism of the reaction.

\section{Reversible Addition Fragmentation Chain Transfer (RAFT)}

Shipp and Matyjaszewski [22] simulated NMP, RAFT, and ATRP of styrene in 1999. The results have been previously discussed under NMP; hence to avoid repetition, the discussion has been omitted in this category. Li et al. [41] modeled RAFT using Monte Carlo method. The group studied the kinetics and chain length distribution of polymers obtained by RAFT process. The results predicted that the molecular weight of the polymers simulated increased in a linear manner with monomer conversion, and they obtained a polydispersity index lower than 1.1. They validated their model against the experimental results reported for styrene and methyl methacrylate. The model was in agreement with the experimental results obtained from the literature. In 2001, Zhang and Ray [42] developed a comprehensive model for RAFT polymerization in tank reactor. The model was used to study process development and design issues. In 2002, Vana et al. [43] used PREDICI to model RAFT polymerization. They simulated conversion, average molecular weights, and full MWD. They studied the circumstances occurring to inhibition and rate retardation that perform as a guide to optimize living polymerization behavior. It was revealed that the ratio of the rate coefficient controlling the addition reaction of propagating radicals to polyRAFT agent was mostly accountable for optimizing the control of the polymerization. As in Figure 4, PREDICI proved that narrow MWD can be obtained by higher values of both the fragmentation rate constant and the polyRAFT agent.

Barner-Kowollik et al. [44] also showed the RAFT process using PREDICI software. They studied the cumyl dithiobenzoate-mediated styrene polymerization at $60^{\circ} \mathrm{C}$ as a case study. They used the experimentally obtained molecular weight distribution for obtaining the rate coefficients by modeling the time-dependent evolution of experimental molecular weight.

Vana et al. [45] simulated RAFT polymerization using the most common mechanism which is suggested by the CSIRO group. Barner-Kowollik et al. simulated the conversion and the molecular weight distribution using PREDICI. They concluded that the values of the rate constants controlling the addition reaction of propagating radicals to polyRAFT agent were the main reason behind optimizing the control of the polymerization.

In 2004, Wulkow et al. [46] modeled the RAFT polymerization using PREDICI. Two major concerns were addressed

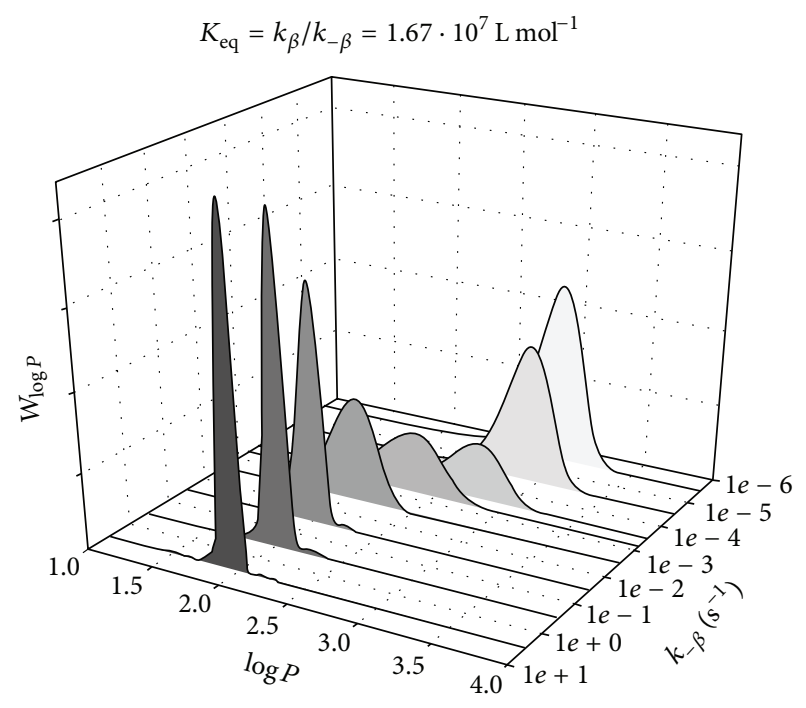

FIGURE 4: Simulated full MWD by changing the values of $k_{\beta}$ and $k_{-\beta}$. All rate constants and reaction data are available in [43].

by Wulkow et al. One was the debate about the nature of the RAFT mechanism and the other was the validity of PREDICI software to model the same. They used the PREDICI software to deduce the rate constants using experimental results. They also explained the mathematical procedure incorporated in PREDICI for modeling.

Pallares et al. [47] compared the reaction mechanism of RAFT using PREDICI and a self-developed program in FORTRAN. They studied all the reactions related to RAFT polymerization. They studied three different major mechanisms expressed in the literature for their modeling study. A comparison of the models for the different reaction mechanisms was clearly presented. The validity of PREDICI to model RAFT polymerization was analyzed and they concluded that PREDICI does have the ability to model RAFT. They concluded that the ambiguous values of the rate constants were the problem more than the PREDICI software.

Jaramillo-Soto et al. [48] simulated RAFT polymerization in super critical carbon dioxide. This was the first attempt to model RAFT polymerization in super critical carbon dioxide using PREDICI. The simulations brought out the kinetic and physical properties for the polymerization of methyl methacrylate using AIBN as an initiator.

Wang et al. published more than one paper on the modeling aspects for RAFT polymerization. The first paper depicted a mathematical model for RAFT scheme which was able to predict the various polymer microstructural properties [49, 50]. They used the method of moments as the modeling technique. The model could forecast the monomer conversion, PDI, and average molecular weight. It also provided thorough statistics about the development of numerous types of chain species during polymerization, such as propagating radical chains, dormant chains, adduct radical chains, and three types of dead chains.

In 2003, Prescott studied the influence of chain length dependent termination in RAFT polymerization [51]. He 
inferred that a higher transfer constant for radical transfer agent (RTA) and short dormant chains show considerably shorter radical lifetimes and produce lesser conversions than systems without RTA, while longer dormant chains lead to an increase in the number of radicals and an extension in their lifetime.

In 2007, Ao et al. [52] modeled the reaction of dithioester and alkoxyamine for better understanding of RAFT polymerization. The kinetics of the model reaction was examined and equated with clean alkoxyamine homolysis with a Monte Carlo simulation. They inferred that a higher concentration of persistent radicals is formed while for a fast RAFT mechanism the concentration is almost similar to that of pure alkoxyamine. They showed that the Monte Carlo simulation is capable of measuring the individual rate constant of the RAFT process.

In 2007, Tobita and Yanase [53] developed a mathematical model using the Monte Carlo method in a disseminated medium assuming ideal miniemulsion. They studied the outcome of particle size on the molecular weight distribution and polymerization rate in NMP and RAFT polymerization. They concluded that rate augmentations by decreasing the particle size were found only for the systems with fast fragmentation of adduct radicals in RAFT system.

Drache et al. [54] implemented a kinetic model for RAFT scheme with the Monte Carlo method. This was a purely simulated work by the group. The group extended their work and published their work corroborating experimental and simulated results using Monte Carlo simulation in a separate publication [55]. This work clearly showed the outstanding arrangement between the experimental and simulated results. The conversion, molecular weight, and concentration of the RAFT species were obtained by FTIR spectroscopy, size exclusion chromatography, and ESR spectroscopy, respectively, for the bulk polymerization of methyl methacrylate. The obtained kinetic data served as parameter set for the Monte Carlo modeling. Their experimental and simulated data were compared and showed excellent agreement.

Modeling diffusion controlled reaction in RAFT polymerizations was studied by Peklak et al. [56]. They conducted experimental analysis coupled with modeling to understand the phenomenon of diffusion controlled reactions in RAFT polymerization. The group used the free volume theory to model diffusion limitations of both RAFT exchange reactions and termination reaction. They compared model predictions with experimental data of methyl methacrylate polymerization and cumyl dithiobenzoate as a RAFT agent.

Another modeling of RAFT polymerization was done by Konkolewicz et al., in 2008 [57]. They presented the argument that even though many mathematical models were developed which corroborated experimental data, there was still compromise in some of the factors. They dealt with commonly used models and their disadvantages in dealing on a realistic scale. They developed a kinetic scheme which assumed that the equilibrium constant is large and only very short radicals may terminate with the intermediate formed during the RAFT process. They concluded that their model was very constant with all investigational data observed till date and suitable for the available quantum calculations.

\section{Atom Transfer Radical Polymerization (ATRP)}

The pioneer in this process was undoubtedly Krzysztof Matyjaszewski. Therefore, it is fitting that we start with his modeling effort in 1999. Matyjaszewski and Shipp [58] developed a kinetic model for ATRP of styrene. They used PREDICI package to simulate the model. ATRP was subjected to the Persistent Radical Effect (PRE). They studied the effect of PRE by taking into consideration the diffusion controlled termination reaction. They concluded that the effect of PRE was not visible since the polymerization goes to high conversion and hence a higher viscosity which conceals the effect of PRE. They also concluded that the thermal initiation does not play major role in ATRP. Around the same time Zhu modeled ATRP by using the method of moments [59]. He simulated properties such as monomer conversion, average molecular weight, and PDI. His model accounted for the effects of side reactions, bimolecular termination, and chain transfer.

In 2000, Matyjaszewski et al. studied the concept of gradient copolymers as it offered a huge potential for manufacturing custom made polymers [60]. Their specific focus was to use atom transfer radical copolymerization to create gradient copolymers with various composition profiles. They simulated atom transfer radical polymerization in both batch and semibatch conditions to make gradient copolymers. The physical properties of gradient copolymers and the potential work in the field of gradient copolymers have been discussed.

In 2002, Lutz and Matyjaszewski modeled the development of chain-end functionality of polymers synthesized by ATRP [61]. They compared several kinetic models and established the effect of specific side reactions involved in ATRP. They concluded that the gradual removal of hydrobromic acid from the polymer end-groups and the thermal self-initiation of the monomer shall affect the chain-end functionality. Even though the polymerization holds numerous characters of a living process, the final and ultimate polymer showed limited functionality. Zhang and Ray have significantly contributed to the field of living polymerization with the perspective of using different reactors for large scale production. A number of their works have been cited before. In this work, they developed a tubular reactor model for living polymerization [62]. They tried to develop a tool which could be utilized for manufacturing tailor-made polymers. They validated their model at the plug flow reactor limit by using batch experimental data for both TEMPO-mediated styrene polymerization and atom transfer radical copolymerization of n-butyl acrylate and styrene. This was one of the first works in modeling atom transfer radical copolymerization to make tailor-made products. They studied the effects of residence time distribution and the effect of Peclet number on both polymer properties and reactor operation.

Al-Harthi et al. carried out a series of experimental and simulation works in the field of atom transfer homo- and copolymerization. Al-Harthi et al. used Monte Carlo simulation predominantly due to its ability to predict the chain length distribution. The group also compared the performance of method of moments and Monte Carlo simulation. 
Al-Harthi et al. put forth a model for ATRP homopolymerization using the Monte Carlo method based on Gillespie algorithm [63]. They modeled the ATRP of styrene and validated their model against their experimental results obtained from their lab. Both the method of moments and Monte Carlo simulation were used for modeling for comparing accuracy. Conversion, PDI, number average molecular weight, and MWD were well represented and gave a very good fit against the experimental results. They concluded that the Monte Carlo simulation is fit for predicting all characteristics of ATRP, including the production of polymers with narrow MWD and the linear increase of the molecular weight with conversion. It was also compared with the method of moments and established that it is more useful than the latter as it is perfect to predict the complete MWD of the polymer.

In 2006, the same group studied the effect of using bifunctional initiators on ATRP [64]. They used the method of moments to predict monomer conversion, average molecular weights, and PDI as a function of polymerization time in batch reactors. The main objective of the work was to count polymerization conditions effects on monomer conversion and polymer properties. They concluded that the bifunctional initiators produced a higher molecular weight polymer at the same conditions while the equilibrium constant was a key factor in controlling the living nature of ATRP.

The same group studied the diffusion effects on ATRP while using bifunctional initiators [65]. They used the method of moments for modeling ATRP while incorporating the free volume theory to study the phenomena of diffusion controlled reactions. A quantitative approach to understand the effect of diffusion on bimolecular termination, activation, deactivation, and propagation reactions was investigated. They validated their model against the solution polymerization of styrene, solution polymerization of MMA, and bulk polymerization of butyl acrylate. They concluded that the diffusion effects enhanced the livingness of the polymerization.

Al-Harthi et al. having used the method of moments to study the effect of bifunctional initiators moved ahead to incorporate the Monte Carlo method for modeling the same [66]. Their primary reason was to understand the chain length distribution which was not available in their previous simulation and to optimize the process of using Monte Carlo. Their work was to compare the method of moments and Monte Carlo results for PDI, conversion, and number average molecular weight. They obtained outstanding agreement between the two methods. They also simulated the performance of monofunctional and bifunctional initiators using the Monte Carlo simulation. They optimized the performance of their algorithm in terms of the size of control volume. These studies led them to a faster algorithm.

Al-Harthi et al. further illustrated the use of bifunctional initiators experimentally and by modeling the ATRP of styrene [67]. Bulk ATRP of styrene was carried out at $110^{\circ} \mathrm{C}$ using both bifunctional and monofunctional initiators. They used the polymerization kinetic data obtained for styrene using mono- and bifunctional initiators and compared them with a mathematical model based on the method of moments and another one using the Monte Carlo simulation. They showed that both models could predict the conversion, PDI, and number average molecular weight very well, and in addition the Monte Carlo simulation was able to predict the MWD accurately. Their stance that a bifunctional initiator produced a high molecular weight polymer was experimentally proven. Later they extended their study to ATRcP of styrene-acrylonitrile copolymers using bifunctional initiators [68]. This was purely an experimental analysis where a simultaneous and sequential addition of the comonomers was investigated. The monofunctional initiators produced a higher molecular weight polymer on simultaneous addition while the bifunctional initiators performed better on sequential addition. This led them to provide a kinetic model for atom transfer radical copolymerization using the method of moments [69]. It was a generic model and could predict conversion, copolymer composition, average molecular weight, and PDI. They assessed the reliability of their model by comparing with investigational data from the literature (copolymerization of n-butyl acrylate and styrene) and from their lab (copolymerization of acrylonitrile and styrene). They concluded that the model proved that the copolymer composition in the ATRcP is independent of the ATRP parameters.

Al-Harthi et al. modeled an interesting concept of using graft copolymers made with ATRP and metallocene catalysts [70]. Monte Carlo simulation has been used to explain the microstructure of polymers prepared with a mixture of ATRP and coordination polymerization. ATRP has been used in the primary stage to produce monodisperse macromonomers, which subsequently copolymerized with ethylene in semibatch mode using the coordination process. The chain length distribution and the grafting density are the vital microstructural details forecasted in this study.

In 2006, Tobita [71] developed a generalized algorithm for modeling the molecular weight distribution in living polymerizations. The model was illustrated with the stable free radical polymerization using the Monte Carlo method. The use of two contrasting radical initiators with respect to their decomposition rates was investigated. The general idea was to find ideal conditions to produce living polymers with a better conversion, narrow MWD, and higher average molecular weights.

In 2007, Chaffey-Millar et al. [72] also developed a novel parallelized approach for the Monte Carlo simulation in order to simulate the entire molecular weight distribution. They developed an algorithm utilizing advanced compiler technology coupled with parallel processing in order to achieve a lesser simulation time as well as utilizing a higher control volume. This parallel Monte Carlo method is in line with the latest progresses in the h-p Galerkin method-based PREDICI software package in terms of computation speed and the details provided. They also concluded that the parallel Monte Carlo method can be fused with the h-p Galerkin methods.

Zhu and coworkers were in parallel with Al-Harthi et al. in the field of the modeling of ATRP. They also published a series of papers on modeling and experimental results in this field. However, they only used the method of moments to study ATRP in batch and semibatch while also providing a quantitative approach to diffusion effects 
in ATRP. In 2007, Wang et al. modeled ATRcP in a semibatch reactor [73]. Their idea was for the production of gradient copolymers with control. Design of the composition versus chain length profile to develop polymer materials with tailor-made properties was studied. They used three different reactivity ratios (representative not experimental) to study the control achieved in a semibatch reactor for tailormade polymers. Zhao et al. recently, in 2009, extended their study to achieve gradient copolymers of MMA and tertiary butyl methacrylate (tBMA) using a semibatch reactor [74]. Delgadillo-Velázquez et al. used the method of moments to model ATRcP in a semibatch reactor using the terminal model. They established the equilibrium constants in the ATRP of MMA and tBMA by the data correlation. DelgadilloVelázquez et al. also produced two works on studying the effect of diffusion on ATRP. In 2002, Delgadillo-Velázquez et al. made a qualitative analysis of diffusion controlled reactions in ATRP initiated by a monofunctional initiator [75]. They considered the equilibrium reactions, propagation, termination, and transfer reactions. They concluded on a similar note as Al-Harthi et al. who later in 2006 modeled diffusion using bifunctional initiators (previously dealt with). They concluded that the general effect of diffusion controlled phenomena in ATRP is to develop the livingness of the system. They used the investigational data from the literature for styrene, methyl acrylate ATRP homopolymerizations, and methyl methacrylate to substantiate the kinetic model. Later, in 2008, Yu et al. modeled the diffusion controlled ATRP which was introduced to cross linking [76].

Controlled free radical polymerization played a major role in surface modifications and functionalization. Zhu and his coworkers paid attention to both experimental and modeling sides of surface modification by grafting mechanisms [77-79]. They used kinetic models to study the termination mechanism for surface initiated ATRP (s-ATRP) and surface initiated RAFT (s-RAFT). The proposed models could predict the thickness of the polymer layer over the initiated surfaces and the rate constants. It was found that the termination of radicals highly depends on the grafting density.

Fu and his group were another team which contributed significantly to the field of the mathematical modeling of living polymerization processes. In 2007 , the group studied the batch and semibatch reactors of styrene experimentally while a mathematical model was also developed [80]. They used a heterogeneous catalyst which provided outstanding molecular weight control. Their experimental and modeling results were in agreement with and provided insight into the polymer reaction engineering aspects in this field.

In 2009, Najafi et al. [81-84] applied the Monte Carlo method to study the effect of chain length dependent termination on ATRP. They inferred that the termination rate constant fell steeply through the course of polymerization when they applied the chain length dependency. A linear relationship is obtained for the molecular weight and monomer conversion. They also inferred that the concentration of the catalyst in lower valence states increases and reaches steady state at a higher conversion. They predicted that the amount of ligand used was also less when

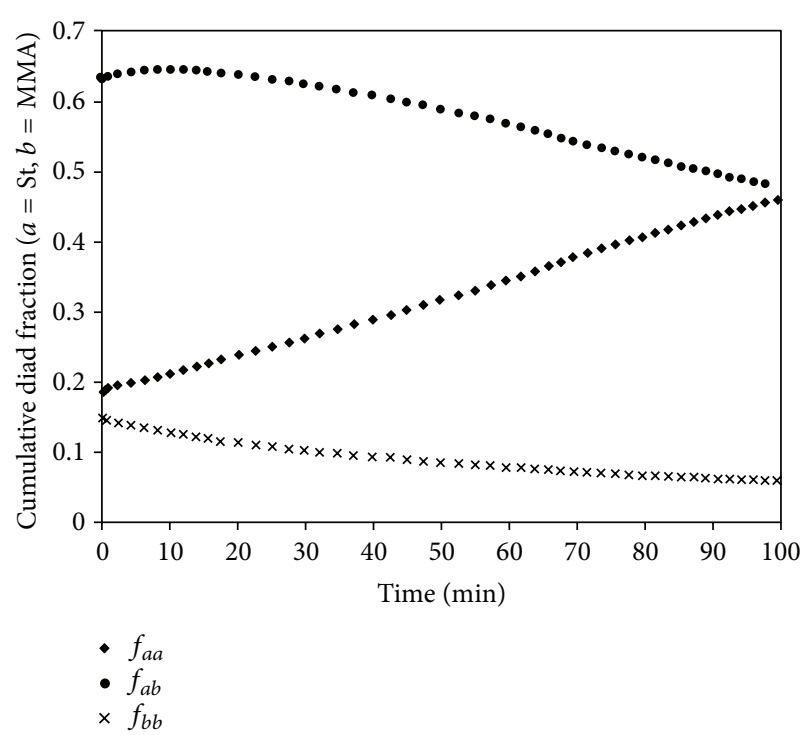

FIGURE 5: Cumulative diad fraction as a function of polymerization time for MMA-St copolymer. The initial monomers molar ratios are $f_{0, \text { MMA }}=0.50$ and $f_{0, \text { st }}=0.50$. The full modeling parameters are available in [85].

chain length dependent termination rate constants were used.

Al-Harthi et al. $[85,86]$ extended their previous studies on modeling ATRP to the copolymer regime. They developed a dynamic Monte Carlo model for ATRcP in a batch and semibatch reactor. The idea and feasibility of producing gradient copolymers using batch and semibatch reactors were also illustrated by using different comonomer feed ratios. The model has been used to find average molecular weights, MWD, copolymer composition, PDI, and comonomer sequence length at any reaction time. Two case studies, poly(styrene-co-methyl methacrylate) and poly(acrylonitrile-co-methyl methacrylate), have been selected to prove the effect of monomers feed ratios on the $\mathrm{CCD}$ of the copolymer. The model was powerful in predicting sequence of the repeating units into the polymeric chains as in Figures 5 and 6.

Zhou et al. [87] used a kinetic model to optimize the experimental conditions and the structure of the fluorinated copolymers that were synthesized using ATRcP. The combination of the experiment and the mathematical modeling shows how powerful are the models to have tailor-made polymer properties.

Monte Carlo simulation was used to determine the gelation in the star polymers that were synthesized using ATRP. Due to complexity of the modeling for star polymers, the agreement between the experiment and the model is only in qualitative agreement. Quantitative comparison needs more parameters to be considered which is not easy in such process [88].

\section{Conclusion}

CFRP has become a hot topic for researchers due to its versatility in producing tailor-made products with considerably 


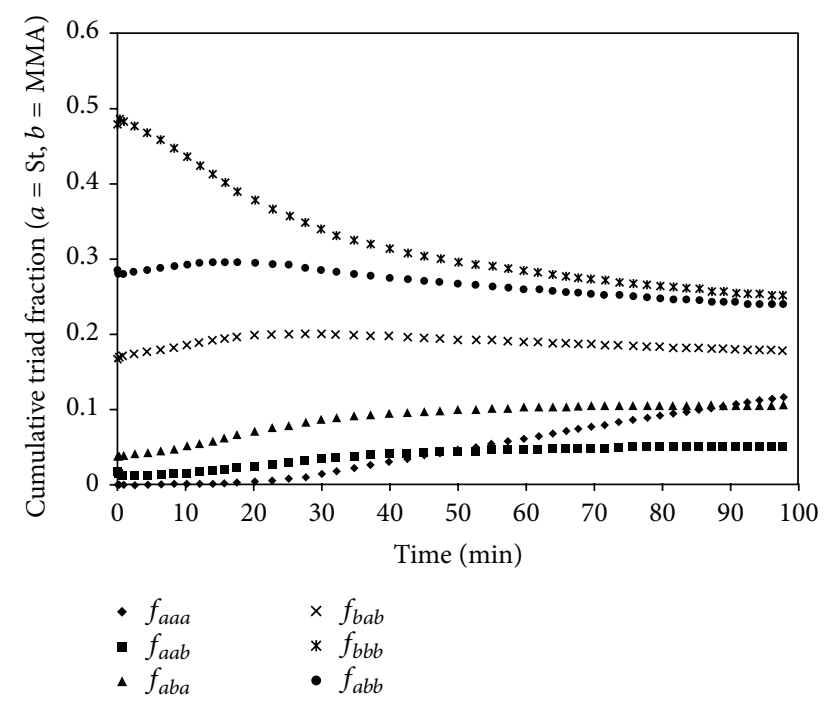

FIGURE 6: Cumulative triad fraction as a function of polymerization time for MMA-St copolymer. The initial monomers molar ratios are $f_{0, \mathrm{MMA}}=0.90$ and $f_{0, \mathrm{st}}=0.10$. The full modeling parameters are available in [85].

low PDI. Researchers are continuously analyzing various catalysts, optimization procedures, and mathematical tools to reduce the cost of manufacturing. It is obvious that mathematical modeling is a short way to understand the nature of the living and controlled polymerizations. Parameter estimation, reactor design, and recipe optimization are very important components that can be determined by mathematical modeling tools. Some modelers of CFRP processes are being used and developed in existing packages like PREDICI. Others utilized the technological advancement of today's computers and developed their codes to model those processes. The comparison between modeling and modeling results proved the efficiency of the existing models under the considered assumptions. With ATRP, NMP, and RAFT becoming the extensive topic of research in the literature, this review is valuable in the field as it provides additional insight from modeling point of view. From the trend and the number of studies that were found in this area over the last quarter century, it is expected that more and more studies will appear in the future with more advanced methodologies.

\section{Conflict of Interests}

The author declares that there is no conflict of interests regarding the publication of this paper.

\section{References}

[1] A. Goto and T. Fukuda, "Kinetics of living radical polymerization," Progress in Polymer Science, vol. 29, no. 4, pp. 329-385, 2004.

[2] K. A. Davis and K. Matyjaszewski, "Statistical, gradient, block, and graft copolymers by controlled/living radical polymerizations," Advances in Polymer Science, vol. 159, pp. 1-13, 2002.
[3] M. Kamigaito, T. Ando, and M. Sawamoto, "Metal-catalyzed living radical polymerization," Chemical Reviews, vol. 101, no. 12 , pp. 3689-3745, 2001.

[4] K. Matyjaszewski, "Macromolecular engineering: from rational design through precise macromolecular synthesis and processing to targeted macroscopic material properties," Progress in Polymer Science, vol. 30, no. 8-9, pp. 858-875, 2005.

[5] D. Benoit, V. Chaplinski, R. Braslau, and C. J. Hawker, "Development of a universal alkoxyamine for 'living' free radical polymerizations," Journal of the American Chemical Society, vol. 121, no. 16, pp. 3904-3920, 1999.

[6] M. Rodlert, E. Harth, I. Rees, and C. J. Hawker, "End-group fidelity in nitroxide-mediated living free-radical polymerizations," Journal of Polymer Science, Part A: Polymer Chemistry, vol. 38, pp. 4749-4763, 2000.

[7] G. Moad, J. Chiefary, Y. K. Chong et al., "Living free radical polymerization with reversible addition-fragmentation chain transfer (the life of RAFT)," Polymer International, vol. 49, pp. 993-1001, 2000.

[8] J. Chiefari, Y. K. Chong, F. Ercole et al., "Living free-radical polymerization by reversible addition-fragmentation chain transfer: the RAFT process," Macromolecules, vol. 31, no. 16, pp. 5559-5562, 1998.

[9] K. Matyjaszewski and J. Xia, "Atom transfer radical polymerization," Chemical Reviews, vol. 101, no. 9, pp. 2921-2990, 2001.

[10] E. Borsig, M. Lazár, M. Čapla, and Š. Florián, "Reinitiation reactions of poly(methyl methacrylate) with labile bound fragments of initiator," Die Angewandte Makromolekulare Chemie, vol. 9, no. 1, pp. 89-95, 1969.

[11] T. Otsu and M. Yoshida, "Role of initiator-transfer agentterminator (iniferter) in radical polymerizations: polymer design by organic disulfides as inferters," Makromolekulare Chemie: Rapid Communications, vol. 3, pp. 127-132, 1982.

[12] T. Otsu and A. Kuriyama, "Polymer design by iniferter technique in radical polymerization: synthesis of $a b$ and aba block copolymers containing random and alternating copolymer sequences," Polymer Journal, vol. 17, no. 1, pp. 97-104, 1984.

[13] M. Lee and Y. Minoura, "Polymerization of vinyl monomers initiated by chromium(II) acetate + organic peroxides," Journal of the Chemical Society, Faraday Transactions 1: Physical Chemistry in Condensed Phases, vol. 74, pp. 1726-1737, 1978.

[14] W. A. Braunecker and K. Matyjaszewski, "Controlled/living radical polymerization: features, developments, and perspectives," Progress in Polymer Science, vol. 32, no. 1, pp. 93-146, 2007.

[15] M. Sawamoto and M. Kamigaito, "Living radical polymerization mediated by transition metals: recent advances," in Controlled Radical Polymerization, vol. 685 of ACS Symposium Series, chapter 18, pp. 296-304, American Chemical Society, 1998.

[16] D. H. Solomon, E. Rizzardo, and P. Cacioli, "Read/write system for optical disc apparatus with fiber optics," US Patent 4,581,529, 1985.

[17] M. K. Georges, R. P. N. Veregin, P. M. Kazmaier, and G. K. Hamer, "Narrow molecular weight resins by a free-radical polymerization process," Macromolecules, vol. 26, no. 11, pp. 2987-2988, 1993.

[18] J. Chiefari, Y. K. Chong, F. Ercole et al., "Living free-radical polymerization by reversible addition-fragmentation chain transfer: the RAFT process," Macromolecules, vol. 31, no. 16, pp. 5559-5562, 1998. 
[19] R. P. N. Veregin, P. G. Odell, L. M. Michalak, and M. K. Georges, "Molecular weight distributions in nitroxide-mediated living free radical polymerization: kinetics of the slow equilibria between growing and dormant chains," Macromolecules, vol. 29, no. 10, pp. 3346-3352, 1996.

[20] T. Fukuda, Y. Tsujii, and T. Miyamoto, "Book of abstracts," in Proceedings of the 213th ACS National Meeting, San Francisco, Calif, USA, April 1997.

[21] J. He, H. Zhang, J. Chen, and Y. Yang, "Monte Carlo simulation of kinetics and chain length distributions in living free-radical polymerization," Macromolecules, vol. 30, no. 25, pp. 8010-8018, 1997.

[22] D. A. Shipp and K. Matyjaszewski, Polymer Preprints, vol. 40, Division of Polymer Chemistry, American Chemical Society, 1999.

[23] J. He, L. Li, and Y. Yang, "Monte Carlo simulation on rate enhancement of nitroxide-mediated living free-radical polymerization," Macromolecular Theory and Simulations, vol. 9, no. 8, pp. 463-468, 2000.

[24] H. Fischer, "Unusual selectivities of radical reactions by internal suppression of fast modes," Journal of the American Chemical Society, vol. 108, no. 14, pp. 3925-3927, 1986.

[25] D. Rueegge and H. Fischer, "Unusual selectivities of radical reactions. Experimental studies on alkyl versus phenoxyl reaction systems," International Journal of Chemical Kinetics, vol. 21, no. 8, pp. 703-714, 1989.

[26] H. Fischer, "The persistent radical effect in 'living' radical polymerization," Macromolecules, vol. 30, no. 19, pp. 5666-5672, 1997.

[27] T. Kothe, S. Marque, R. Martschke, M. Popov, and H. Fischer, "Radical reaction kinetics during homolysis of $\mathrm{N}$ alkoxyamines: verification of the persistent radical effect," Journal of the Chemical Society, Perkin Transactions 2, no. 7, pp. 1553-1559, 1998.

[28] T. Kothe, R. Martschke, and H. Fischer, "Photoreactions of the decatungstate anion W10O324- with organic substrates in solution studied by EPR and kinetic absorption spectroscopy: an example for the persistent radical effect," Journal of the Chemical Society. Perkin Transactions 2, no. 3, pp. 503-507, 1998.

[29] H. Fischer, "The persistent radical effect in controlled radical polymerizations," Journal of Polymer Science Part A: Polymer Chemistry, vol. 37, no. 13, pp. 1885-1901, 1999.

[30] J. Bonilla, E. Saldívar, A. Flores-Tlacuahuac, E. Vivaldo-Lima, R. Pfaendner, and F. Tiscareño-Lechuga, "Detailed modeling, simulation, and parameter estimation of nitroxide mediated living free radical polymerization of styrene," Polymer Reaction Engineering, vol. 10, no. 4, pp. 227-263, 2002.

[31] T. Schulte, C. A. Knoop, and A. Studer, "Nitroxide-mediated living free-radical polymerization of styrene: a systematic study of the variation of the alkoxyamine concentration," Journal of Polymer Science, Part A: Polymer Chemistry, vol. 42, no. 13, pp. 3342-3351, 2004.

[32] Y. Guillaneuf, D. Gigmes, S. R. A. Marque, P. Tonlo, and D. Bertin, "Nitroxide-mediated polymerization of methyl methacrylate using an SG1-based alkoxyamine: how the penultimate effect could lead to uncontrolled and unliving polymerization," Macromolecular Chemistry and Physics, vol. 207, no. 14, pp. 1278-1288, 2006.

[33] D. Gigmes, D. Bertin, C. Lefay, and Y. Guillaneuf, "Kinetic modeling of nitroxide-mediated polymerization: conditions for living and controlled polymerization," Macromolecular Theory and Simulations, vol. 18, no. 7-8, pp. 402-419, 2009.
[34] R. Lemoine-Nava, A. Flores-Tlacuahuac, and E. SaldívarGuerra, "Non-linear bifurcation analysis of the living nitroxidemediated radical polymerization of styrene in a CSTR," Chemical Engineering Science, vol. 61, no. 2, pp. 370-387, 2006.

[35] M. Zhang and W. H. Ray, "Modeling of 'living' free-radical polymerization processes. I. Batch, semibatch, and continuous tank reactors," Journal of Applied Polymer Science, vol. 86, no. 7, pp. 1630-1662, 2002.

[36] Y. Fu, M. F. Cunningham, and R. A. Hutchinson, "Modeling of nitroxide-mediated semibatch radical polymerization," Macromolecular Reaction Engineering, vol. 1, no. 2, pp. 243-252, 2007.

[37] M. Asteasuain, M. Soares, M. K. Lenzi et al., "Living free radical polymerization in tubular reactors. I. Modeling of the complete molecular weight distribution using probability generating functions," Macromolecular Reaction Engineering, vol. 1, pp. 622-634, 2007.

[38] M. Asteasuain, M. Soares, M. K. Lenzi et al., “'Living’ radical polymerization in tubular reactors, 2-process optimization for tailor-made molecular weight distributions," Macromolecular Reaction Engineering, vol. 2, no. 5, pp. 414-421, 2008.

[39] M. Roa-Luna, A. Nabifar, N. T. McManus, E. Vivaldo-Lima, L. M. F. Lona, and A. Penlidis, "Effect of the addition of inert or TEMPO-capped prepolymer on polymerization rate and molecular weight development in the nitroxide-mediated radical polymerization of styrene," Journal of Applied Polymer Science, vol. 109, no. 6, pp. 3665-3678, 2008.

[40] J. Belincanta-Ximenes, P. V. R. Mesa, L. M. F. Lona, E. VivaldoLima, N. T. McManus, and A. Penlidis, "Simulation of styrene polymerization by monomolecular and bimolecular nitroxidemediated radical processes over a range of reaction conditions," Macromolecular Theory and Simulations, vol. 16, no. 2, pp. 194208, 2007.

[41] L. Li, J. P. He, and Y. L. Yang, "Monte Carlo simulation on living radical polymerization with RAFT process," Chemical Journal of Chinese Universities (Chinese Edition), vol. 21, pp. 1146-1148, 2000.

[42] M. Zhang and W. H. Ray, "Modeling of 'living' free-radical polymerization with RAFT chemistry," Industrial \& Engineering Chemistry Research, vol. 40, no. 20, pp. 4336-4352, 2001.

[43] P. Vana, T. P. Davis, and C. Barner-Kowollik, "Kinetic analysis of reversible addition fragmentation chain transfer (RAFT) polymerizations: conditions for inhibition, retardation, and optimum living polymerization," Macromolecular Theory and Simulations, vol. 11, no. 8, pp. 823-835, 2002.

[44] C. Barner-Kowollik, J. F. Quinn, D. R. Morsley, and T. P. Davis, "Modeling the reversible addition-fragmentation chain transfer process in cumyl dithiobenzoate-mediated styrene homopolymerizations: assessing rate coefficients for the additionfragmentation equilibrium," Journal of Polymer Science Part A: Polymer Chemistry, vol. 39, no. 9, pp. 1353-1365, 2001.

[45] P. Vana, T. P. Davis, and C. Barner-Kowollik, "Kinetic analysis of reversible addition fragmentation chain transfer (RAFT) polymerizations: conditions for inhibition, retardation, and optimum living polymerization," Macromolecular Theory and Simulations, vol. 11, no. 8, pp. 823-835, 2002.

[46] M. Wulkow, M. Busch, T. P. Davis, and C. Barner - Kowollik, "Implementing the reversible addition-fragmentation chain transfer process in PREDICI," Journal of Polymer Science Part A: Polymer Chemistry, vol. 42, no. 6, pp. 1441-1448, 2004.

[47] J. Pallares, J. Gabriel, F. Citlalli, L. E. Vivaldo, L. M. F. Lona, and A. Penlidis, "Comparison of reaction mechanisms for reversible addition-fragmentation chain transfer polymerization using 
modeling tools," Journal of Macromolecular Science A, vol. 43, pp. 1293-1322, 2006.

[48] G. Jaramillo-Soto, M. L. Castellanos-Cárdenas, P. R. GarcíaMorán, E. Vivaldo-Lima, G. Luna-Bárcenas, and A. Penlidis, "Simulation of RAFT dispersion polymerization in supercritical carbon dioxide," Macromolecular Theory and Simulations, vol. 17, no. 6, pp. 280-289, 2008.

[49] A. R. Wang and S. Zhu, "Modeling the reversible additionfragmentation transfer polymerization process," Journal of Polymer Science A: Polymer Chemistry, vol. 41, no. 11, pp. 1553-1566, 2003.

[50] A. R. Wang and S. Zhu, "Calculations of monomer conversion and radical concentration in reversible addition-fragmentation chain transfer radical polymerization," Macromolecular Theory and Simulations, vol. 12, no. 9, pp. 663-668, 2003.

[51] S. W. Prescott, "Chain-length dependence in living/controlled free-radical polymerizations: physical manifestation and monte carlo simulation of reversible transfer agents," Macromolecules, vol. 36, no. 25, pp. 9608-9621, 2003.

[52] Y. Ao, J. He, X. Han et al., "Kinetic analysis of the cross reaction between dithioester and alkoxyamine by a Monte Carlo simulation," Journal of Polymer Science, Part A: Polymer Chemistry, vol. 45, no. 3, pp. 374-387, 2007.

[53] H. Tobita and F. Yanase, "Monte Carlo simulation of controlled/living radical polymerization in emulsified systems," Macromolecular Theory and Simulations, vol. 16, no. 4, pp. 476488, 2007.

[54] M. Drache, K. Drees, and G. Schmidt-Naake, "Implementation of a Kinetic model of the RAFT polymerization with a Monte Carlo method," in Proceedings of the 8th International Workshop on Polymer Reaction Engineering, October 2004.

[55] M. Drache, P. Vana, and G. Schmidt-Naake, "Modeling RAFT polymerization kinetics via Monte-Carlo methods," in Proceedings of the 7th World Congress of Chemical Engineering, 84560/1, Glasgow, Scotland, July 2005.

[56] A. D. Peklak, A. Butté, G. Storti, and M. Morbidelli, "Gel effect in the bulk reversible addition-fragmentation chain transfer polymerization of methyl methacrylate: modeling and experiments," Journal of Polymer Science A: Polymer Chemistry, vol. 44, no. 3, pp. 1071-1085, 2006.

[57] D. Konkolewicz, B. S. Hawkett, A. Gray-Weale, and S. Perrier, "RAFT polymerization kinetics: combination of apparently conflicting models," Macromolecules, vol. 41, no. 17, pp. 64006412, 2008.

[58] D. A. Shipp and K. Matyjaszewski, "Kinetic analysis of controlled/'living' radical polymerizations by simulations. 1 . The importance of diffusion-controlled reactions," Macromolecules, vol. 32, no. 9, pp. 2948-2955, 1999.

[59] S. Zhu, "Modeling of modular weight development in atom transfer radical polymerization," Macromolecular Theory and Simulations, vol. 8, no. 1, pp. 29-37, 1999.

[60] K. Matyjaszewski, M. J. Ziegler, S. V. Arehart, D. Greszta, and T. Pakula, "Gradient copolymers by atom transfer radical copolymerization," Journal of Physical Organic Chemistry, vol. 13, no. 12, pp. 775-786, 2000.

[61] J.-F. Lutz and K. Matyjaszewski, "Kinetic modeling of the chainend functionality in atom transfer radical polymerization," Macromolecular Chemistry and Physics, vol. 203, no. 10-11, pp. 1385-1395, 2002.

[62] M. Zhang and W. H. Ray, "Modeling of 'living' free-radical polymerization processes. II: tubular reactors," Journal of Applied Polymer Science, vol. 86, no. 5, pp. 1047-1056, 2002.
[63] M. Al-Harthi, J. B. P. Soares, and L. C. Simon, "Dynamic Monte Carlo simulation of atom-transfer radical polymerization," Macromolecular Materials and Engineering, vol. 291, no. 8, pp. 993-1003, 2006.

[64] M. Al-Harthi, J. B. P. Soares, and L. C. Simon, "Mathematical modeling of atom-transfer radical polymerization using bifunctional initiators," Macromolecular Theory and Simulations, vol. 15, no. 3, pp. 198-214, 2006.

[65] M. Al-Harthi, J. B. P. Soares, and L. C. Simon, "Modeling of atom transfer radical polymerization with bifunctional initiators: diffusion effects and case studies," Macromolecular Chemistry and Physics, vol. 207, no. 5, pp. 469-483, 2006.

[66] M. Al-Harthi, J. Soares, and L. Simon, "Dynamic Monte Carlo simulation of ATRP with bifunctional initiators," Macromolecular Reaction Engineering, vol. 1, no. 1, pp. 95-105, 2007.

[67] M. Al-Harthi, L. S. Cheng, J. B. P. Soares, and L. C. Simon, "Atom-transfer radical polymerization of styrene with bifunctional and monofunctional initiators: Experimental and mathematical modeling results," Journal of Polymer Science A: Polymer Chemistry, vol. 45, no. 11, pp. 2212-2224, 2007.

[68] M. Al-Harthi, A. Sardashti, J. B. P. Soares, and L. C. Simon, "Atom transfer radical polymerization (ATRP) of styrene and acrylonitrile with monofunctional and bifunctional initiators," Polymer, vol. 48, no. 7, pp. 1954-1961, 2007.

[69] M. Al-Harthi, J. Soares, and L. Simon, "Mathematical modeling of atom-transfer radical copolymerization," Macromolecular Reaction Engineering, vol. 1, no. 4, pp. 468-479, 2007.

[70] M. Al-Harthi, J. B. P. Soares, and L. C. Simon, "Dynamic Monte Carlo simulation of graft copolymers made with ATRP and metallocene catalysts," Macromolecular Symposia, vol. 243, pp. 83-90, 2006.

[71] H. Tobita, "Molecular weight distribution of living radical polymers," Macromolecular Theory and Simulations, vol. 15, no. 1, pp. 23-31, 2006.

[72] H. Chaffey-Millar, D. Stewart, M. M. T. Chakravarty, G. Keller, and C. Barner-Kowollik, "A parallelised high performance Monte Carlo simulation approach for complex polymerisation kinetics," Macromolecular Theory and Simulations, vol. 16, no. 6, pp. 575-592, 2007.

[73] R. Wang, Y. Luo, B.-G. Li, and S. Zhu, "Control of gradient copolymer composition in ATRP using semibatch feeding policy," AIChE Journal, vol. 53, no. 1, pp. 174-186, 2007.

[74] Y. Zhao, Y.-W. Luo, C. Ye, B.-G. Li, and S. Zhu, "Model-based design and synthesis of gradient MMA/tBMA copolymers by computer-programmed semibatch atom transfer radical copolymerization," Journal of Polymer Science, Part A: Polymer Chemistry, vol. 47, no. 1, pp. 69-79, 2009.

[75] O. Delgadillo-Velázquez, E. Vivaldo-Lima, I. A. QuinteroOrtega, and S. Zhu, "Effects of diffusion-controlled reactions on atom-transfer radical polymerization," AIChE Journal, vol. 48, no. 11, pp. 2597-2608, 2002.

[76] Q. Yu, Z. Qin, J. Li, and S. Zhu, "Diffusion-controlled atom transfer radical polymerization with crosslinking," Polymer Engineering and Science, vol. 48, no. 7, pp. 1254-1260, 2008.

[77] D. Zhou, X. Gao, W.-J. Wang, and S. Zhu, "Termination of surface radicals and kinetic modeling of ATRP grafting from flat surfaces by addition of deactivator," Macromolecules, vol. 45, no. 3, pp. 1198-1207, 2012.

[78] X. Gao, W. Feng, S. Zhu, H. Sheardown, and J. L. Brash, "Kinetic modeling of surface-initiated atom transfer radical polymerization," Macromolecular Reaction Engineering, vol. 4, no. 3-4, pp. 235-250, 2010. 
[79] D. Zhou, E. Mastan, and S. Zhu, "Termination of surface radicals and kinetic analysis of surface-initiated RAFT polymerization on flat surfaces," Macromolecular Theory and Simulations, vol. 21, no. 9, pp. 602-614, 2012.

[80] Y. Fu, M. F. Cunningham, and R. A. Hutchinson, "Atomtransfer radical batch and semibatch polymerization of styrene," Macromolecular Reaction Engineering, vol. 1, pp. 425-429, 2007.

[81] M. Najafi, V. Haddadi-Asl, M. Salami-Kalajahi, and H. R. Mamaghani, "Application of the Monte Carlo simulation method to the investigation of the effect of chain-length-dependent bimolecular termination on ATRP," E-Polymers, vol. 9, no. 1, pp. 355-374, 2013.

[82] M. Najafi, H. Roghani-Mamaqani, V. Haddadi-Asl, and M. Salami-Kalajahi, "A simulation of kinetics and chain length distribution of styrene FRP and ATRP: chain-length-dependent termination," Advances in Polymer Technology, vol. 30, no. 4, pp. 257-268, 2011.

[83] M. Najafi, H. Roghani-Mamaqani, M. Salami-Kalajahi, and V. Haddadi-Asl, "A comprehensive Monte Carlo simulation of styrene atom transfer radical polymerization," Chinese Journal of Polymer Science, vol. 28, no. 4, pp. 483-497, 2010.

[84] M. Najafi, H. Roghani-Mamaqani, M. Salami-Kalajahi, and V. Haddadi-Asl, "An exhaustive study of chain-length-dependent and diffusion-controlled free radical and atom-transfer radical polymerization of styrene," Journal of Polymer Research, vol. 18, no. 6, pp. 1539-1555, 2011.

[85] M. Al-Harthi, M. J. Khan, S. H. Abbasi, and J. B. P. Soares, "Gradient copolymers by ATRP in semibatch reactors: dynamic Monte Carlo simulation," Macromolecular Reaction Engineering, vol. 3, no. 4, pp. 148-159, 2009.

[86] M. A. Al-Harthi, J. K. Masihullah, S. H. Abbasi, and J. B. P. Soares, "Dynamic Monte Carlo simulation of ATRP in a batch reactor," Macromolecular Theory and Simulations, vol. 18, no. 6, pp. 307-316, 2009.

[87] Y.-N. Zhou, Z.-H. Luo, and J.-H. Chen, “Theoretical modeling coupled with experimental study on the preparation and characterization comparison of fluorinated copolymers: effect of chain structure on copolymer properties," AIChE Journal, vol. 59, no. 8, pp. 3019-3033, 2013.

[88] P. Polanowski, J. K. Jeszka, and K. Matyjaszewski, "Star polymer synthesis and gelation in ATRP copolymerization: Monte Carlo simulations," Polymer, vol. 54, no. 8, pp. 1979-1986, 2013. 

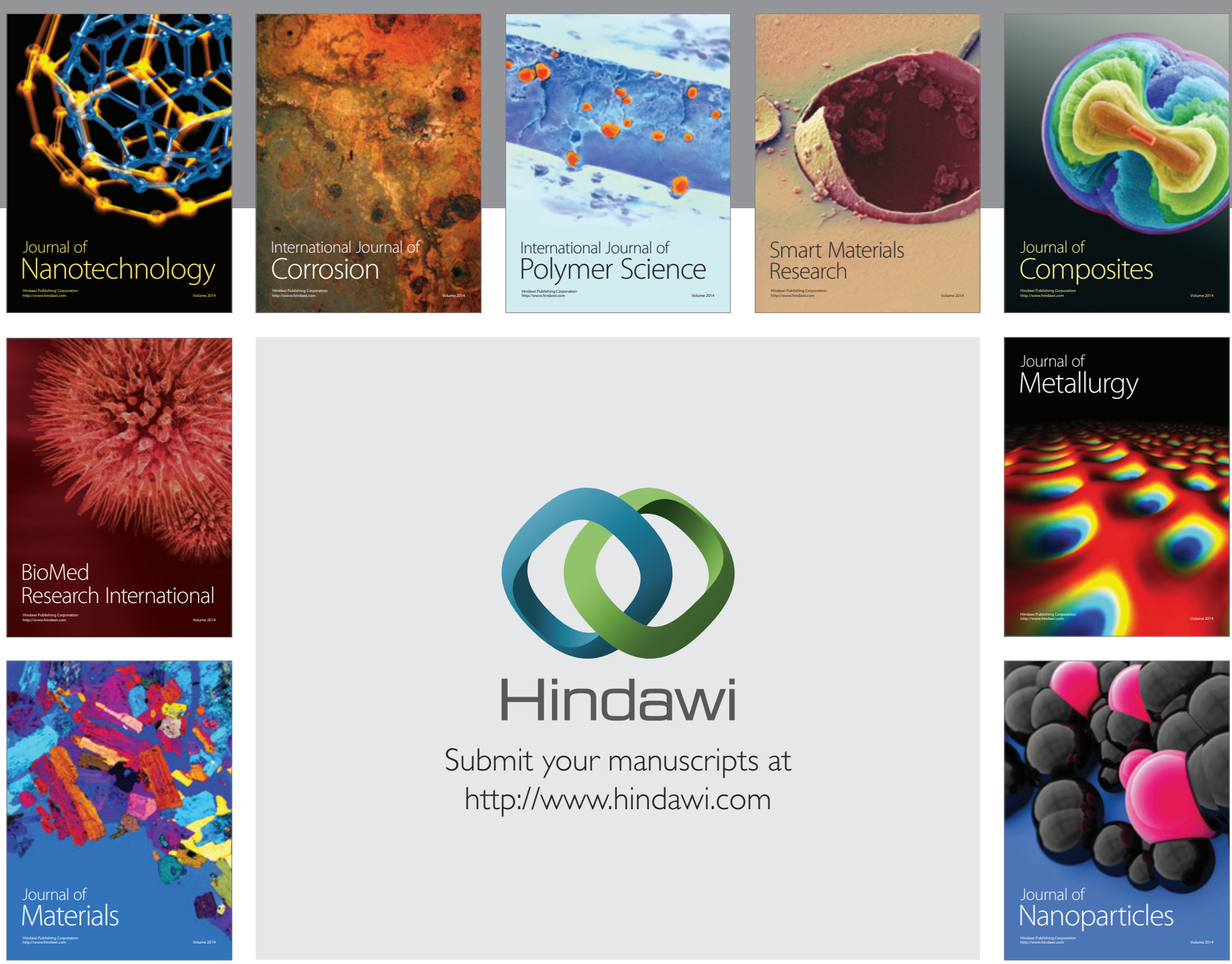

Submit your manuscripts at http://www.hindawi.com
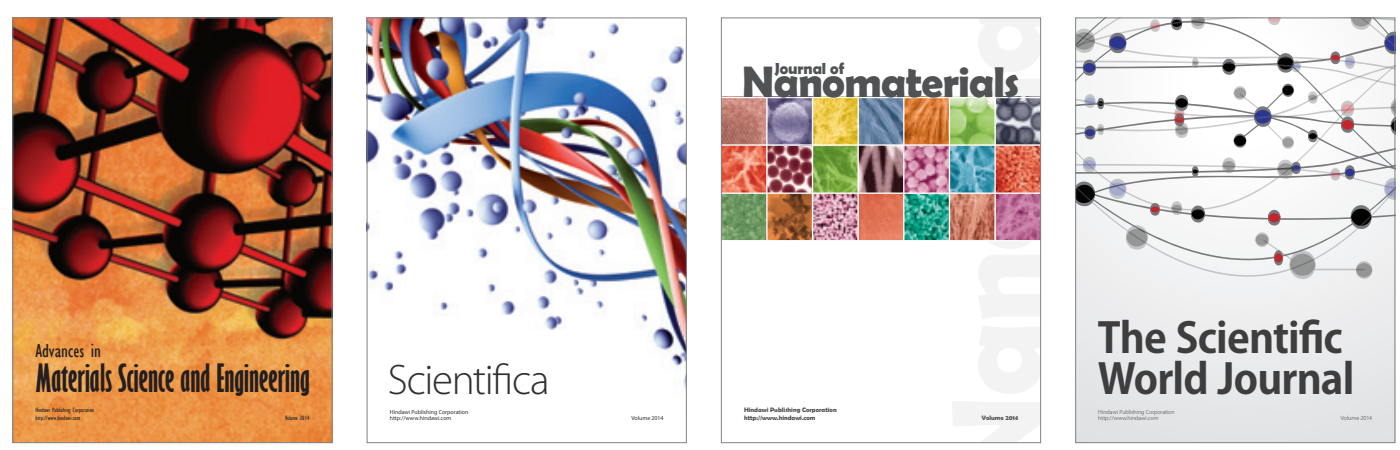

\section{The Scientific World Journal}
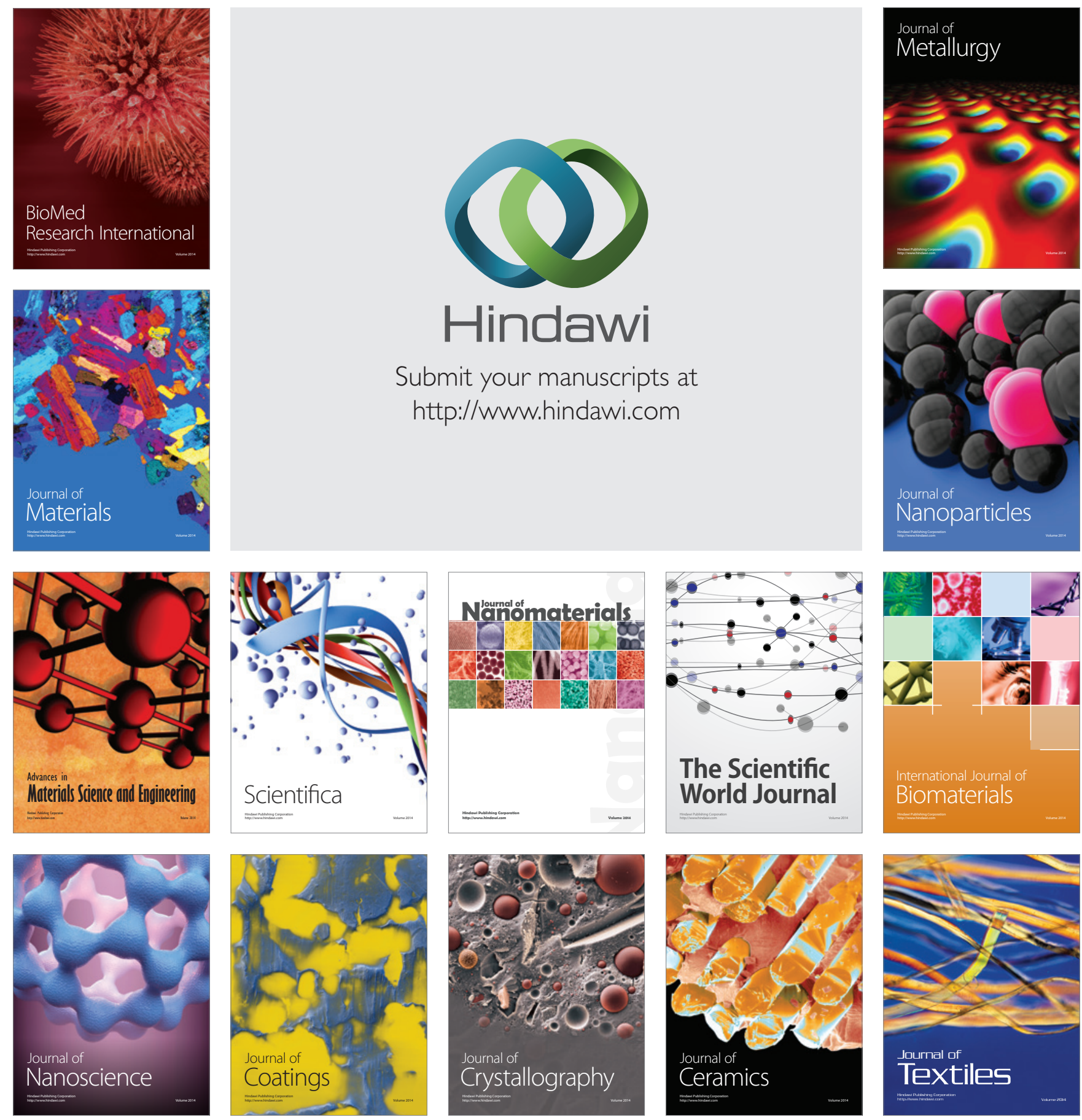